\title{
Metástasis coroideas como primera manifestación de adenocarcinoma de páncreas: reporte de un caso
}

\section{Choroidal metastases as the first manifestation of pancreatic adenocarcinoma: a case report}

\author{
José R. Mier-Bolio*, José M. Arroyo-González, Elizabeth Baques-Guillén, José F. Valdez-López y \\ Gerardo Rivera-Arroyo \\ Servicio de Retina y Vitreo, Hospital Central Militar, Ciudad de México, México
}

\section{Resumen}

Objetivo: Reportar el caso de un paciente de 26 años que acudió por presentar baja visual súbita unilateral, asociada a fotofobia intensa y cefalea, como primera manifestación de metástasis coroideas secundarias a adenocarcinoma de páncreas. Caso clínico: Mediante un trabajo multidisciplinario, estudios auxiliares tanto oftalmológicos como oncológicos y la realización de una biopsia hepática se llegó al diagnóstico de metástasis sistémicas y coroideas secundarias a adenocarcinoma de páncreas. Conclusiones: Este es el primer caso documentado en México de un paciente que presenta como primera manifestación baja visual unilateral secundaria a metástasis coroideas por adenocarcinoma de páncreas.

Palabras clave: Metástasis coroideas. Cáncer de páncreas. Fotofobia. Mortalidad.

\begin{abstract}
Purpose: To report the clinical case of a 26-year-old patient, who presented with unilateral vision loss, associated with intense photophobia and headache as the first manifestation of choroidal metastases secondary to pancreatic adenocarcinoma. Case report: Through a multidisciplinary approach, ophthalmological and oncological ancillary studies and the performance of a liver biopsy, a diagnosis of systemic and choroidal metastases secondary to pancreatic adenocarcinoma was made. Conclusions: This is the first documented case of a metastatic pancreatic adenocarcinoma presenting with unilateral vision loss in Mexico.
\end{abstract}

Key words: Choroidal metastases. Pancreatic cancer. Photophobia. Mortality.

\section{Introdución}

Las metástasis coroideas (MC) se consideran actualmente como la tumoración intraocular maligna más frecuente del adulto ${ }^{1-5}$. Por estudios post mortem se cree que la prevalencia varía entre un $8 \%$ y un $10 \%$ en los pacientes con metástasis sistémicas² ${ }^{2}$ Las MC tienen mayor frecuencia en el sexo femenino, con una edad promedio de 53 años y con antecedente de neoplasia ${ }^{2-5}$.

Los tumores que se han reportado con mayor riesgo de presentar metástasis coroideas son el cáncer de

Correspondencia:

*José R. Mier-Bolio

Periférico Blvrd Manuel Ávila Camacho, s/n

Militar, Miguel Hidalgo

Fecha de recepción: 27-07-2020

Fecha de aceptación: 09-11-2020

DOI: 10.24875/RMO.M21000165
Disponible en internet: 12-04-2021 Rev Mex Oftalmol. (ahead of print) www.rmo.com.mx 
mama, aproximadamente en un $50 \%$ del total de los casos, y el cáncer pulmonar, en un 22-29\% $\%^{1-5}$. En la literatura universal se han documentado pocos casos de MC secundarias a adenocarcinoma de páncreas como primera manifestación de este cáncer ${ }^{6}$.

La sintomatología ocular ocasionada por las MC suele ser baja visual o visión borrosa en un $80 \%$, miodesopsias o fotopsias en menos del $10 \%$, fotofobia en un $5 \%$, dolor ocular en menos del $5 \%$ e incluso un $30 \%$ de los pacientes pueden estar totalmente asintomáticos ${ }^{1-4}$.

Las manifestaciones clínicas oftalmológicas dependerán de múltiples factores, como el tipo de tumor primario y el nivel de invasión tumoral. Regularmente se observa una masa subrretiniana $(72 \%)$, de coloración amarillenta (94\%), asociada a líquido subrretiniano $(73 \%)^{5}$. En promedio se presentan 1.6 lesiones de forma unilateral, involucrando el polo posterior, en la región macular y temporal al ecuador ${ }^{3-5}$.

El diagnóstico suele realizarse de manera multidisciplinaria; cuando existe el antecedente de neoplasia suele ser más sencillo y dirigido². Si la forma de presentación es por la afectación ocular, suele ser más complejo y se realiza con estudios auxiliares oftalmológicos y sistémicos ${ }^{2-5}$. El diagnóstico diferencial de las MC incluye enfermedades retinianas inflamatorias e infecciosas, y otros tumores intraoculares ${ }^{7}$.

El tratamiento dependerá del tumor primario, de si hay otros sitios de metástasis, del grado de función visual y de las condiciones sistémicas del paciente ${ }^{2}$. El pronóstico para los pacientes con MC es malo; en general, la supervivencia varía de meses a 5 años ${ }^{1-5}$.

\section{Caso clínico}

Varón de 26 años sin antecedentes médicos ni oftalmológicos de importancia. Acude por presentar baja visual súbita de 20 días de evolución del ojo izquierdo (OI) asociada a fotofobia intensa y cefalea. Presentaba una agudeza visual del ojo derecho (OD) logMAR 0.0, con el Ol cuenta dedos a $50 \mathrm{~cm}$.

Los reflejos pupilares fotomotor y consensual se encontraban sin alteraciones en el OD y disminuidos en el Ol. La visión cromática se evaluó por medio de las laminillas de Ishihara, obteniendo $8 / 8$ en el OD y $0 / 8$ en el OI. El segmento anterior de ambos ojos se encontraba sin alteraciones. La presión intraocular por medio de tonometría de Goldmann era de $12 \mathrm{mmHg}$ en el OD y de $13 \mathrm{mmHg}$ en el Ol.

En el fondo de ojo se observó el OD sin alteraciones y en el Ol coriorretinitis con infiltración del nervio óptico, con datos de desprendimiento de retina seroso

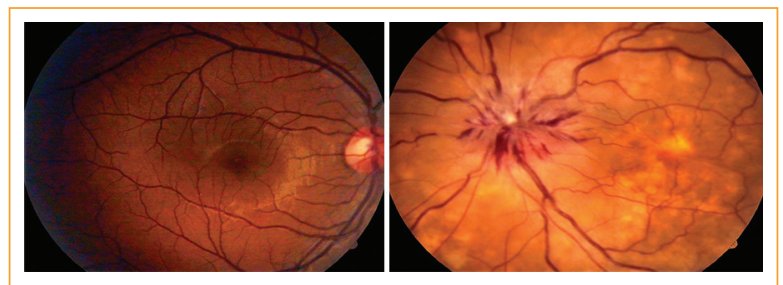

Figura 1. Imagen clínica del polo posterior de ambos ojos.

localizado en el polo posterior (Fig. 1). Se le realizó angiografía con fluoresceína sódica, en la cual se detectaron dos datos de hiperfluorescencia del OI: fenómeno de fuga a nivel del disco óptico y fenómenos de acúmulo generalizado en el polo posterior. Se le realizó tomografía de coherencia óptica de dominio espectral macular, en la cual el OD se encontró sin alteraciones y el Ol mostró datos de disrupción de la membrana limitante interna, pérdida de la línea elipsoide, puntos hiperreflécticos probablemente compatibles con los segmentos externos de los fotorreceptores, así como imagen de doble joroba en el epitelio pigmentario de la retina. Posteriormente se le realizó ultrasonido ocular en modos A y B (Fig. 2).

Por medio de laboratorios sistémicos se descartaron enfermedades infecto-contagiosas (VDRL [Venereal disease research laboratory], TORCH [toxoplasmosis, otras infecciones, rubéola, citomegalovirus, herpes], sífilis, citomegalovirus, Chikungunya, dengue y virus de la inmunodeficiencia humana). La biometría hemática mostró anemia leve y un patrón infiltrativo por las pruebas de funcionamiento hepático. El paciente presentaba una lesión en el cuero cabelludo, ulcerada, con secreción hemática y datos de necrosis, de aproximadamente de $3 \times 3 \mathrm{~cm}$, motivo por el cual se solicitó interconsulta al servicio de dermatología, donde realizaron una biopsia escisional de la lesión del cuero cabelludo, que se reportó como carcinoma anexial microquístico, probablemente secundario a otra tumoración.

A continuación fue valorado por el servicio de oncología médica, donde se decidió realizar una tomografía computarizada toracoabdominal con contraste, en la cual se observó un parénquima hepático heterogéneo con múltiples lesiones hipodensas, de distribución aleatoria, afectando el hígado y la cabeza del páncreas. Los marcadores tumorales sanguíneos mostraron unos valores de CA19-9 de 194,000 U/ml (valores de referencia: 0-37), antígeno carcinoembrionario de $568 \mathrm{ng} / \mathrm{ml}$ (valores de referencia: 0-3) y alfa-fetoproteína y antígeno prostático específico dentro de los valores 


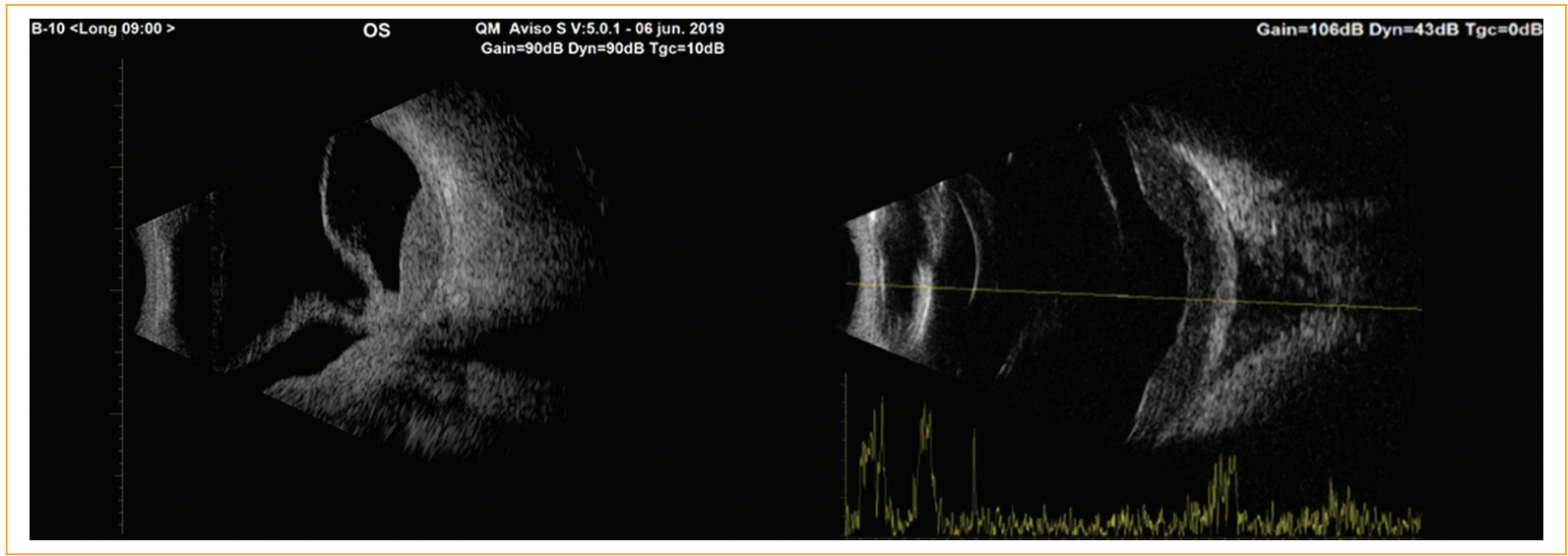

Figura 2. Ultrasonido ocular que muestra un desprendimiento de retina seroso, de la papila a la periferia de $360^{\circ}, y$ una lesión coroidea en el polo posterior de mediana reflectividad, sin vascularidad que invada la esclera y la grasa orbitaria.

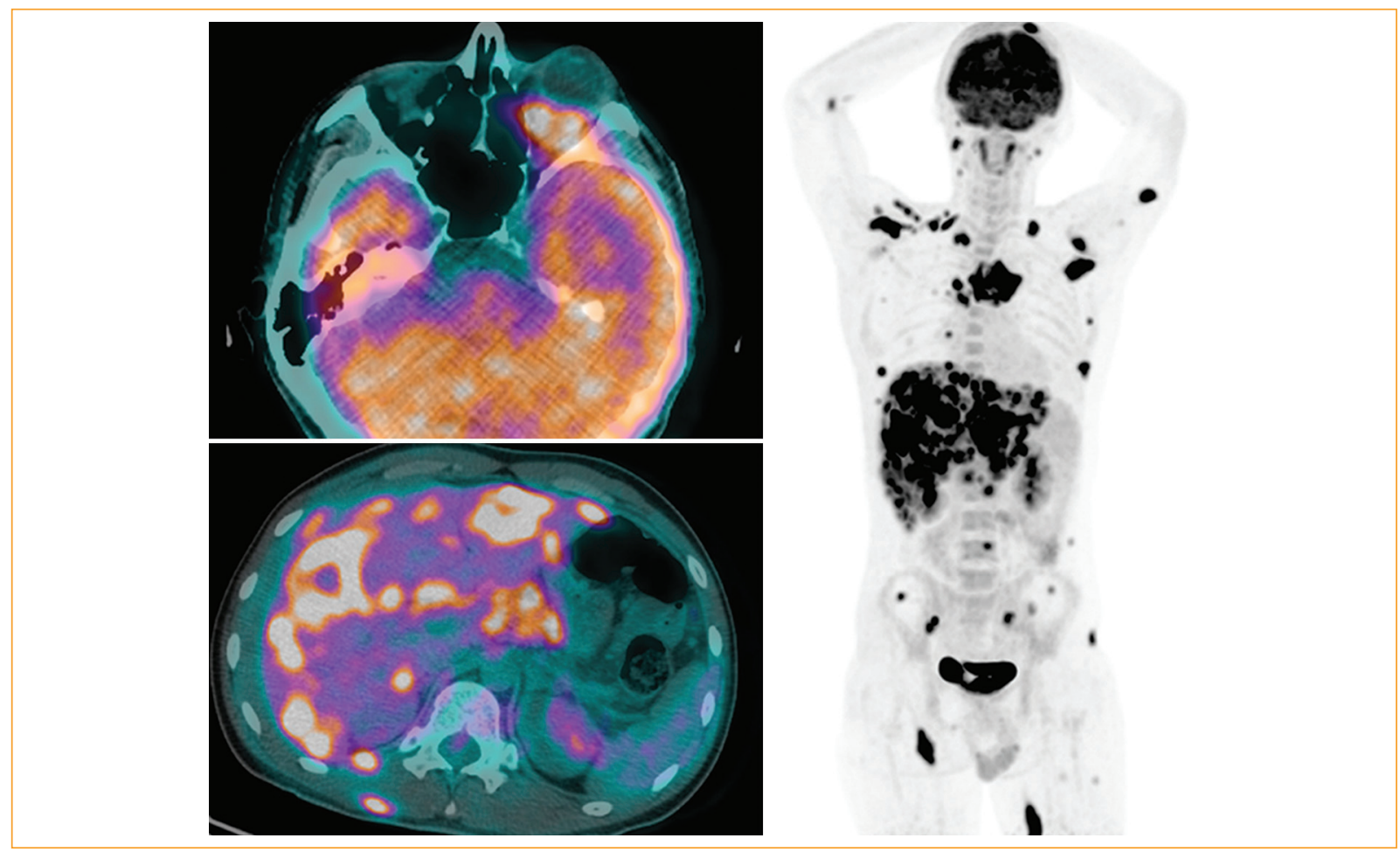

Figura 3. Tomografía por emisión de positrones que muestra múltiples lesiones hipercaptantes.

normales. Se le realizaron una tomografía por emisión de positrones (Fig. 3) y una biopsia hepática (Fig. 4).

Debido al diagnóstico de adenocarcinoma de páncreas en estadio IV, con metástasis en hígado, tejido óseo y globo ocular, se le dio tratamiento con cinco ciclos de quimioterapia con el esquema m-FOLFIRINOX (oxaliplatino, ácido fólico, irinotecán bisemanal y 5-fluorouracilo). El pronóstico establecido de sobrevida del paciente es del $5 \%$ a 5 años.

\section{Discusión}

Son pocos los casos documentados en todo el mundo de $\mathrm{MC}$ secundarias a cáncer de páncreas. 


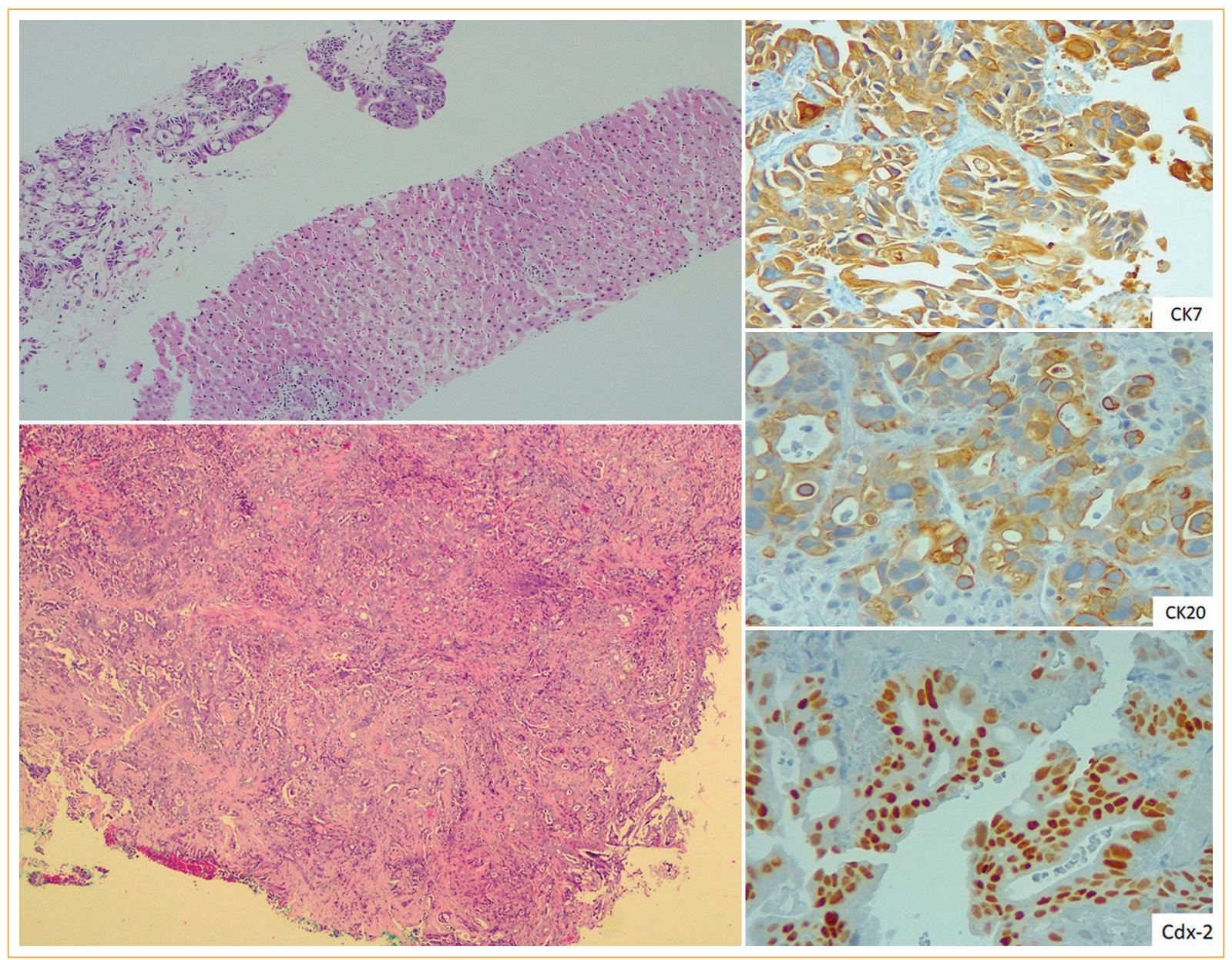

Figura 4. Biopsia de hígado por aguja gruesa infiltrada por adenocarcinoma de fenotipo pancreaticobiliar. Inmunomarcación positiva citoplasmática para CK20 y CK7, y nuclear para CDX2.

Presentamos el primer reporte de caso en un paciente mexicano.

Shields, et al. ${ }^{5}$ realizaron una de las revisiones más importantes de la literatura internacional sobre MC, en la cual describieron las características clínicas y los resultados de supervivencia de 2214 casos correspondientes a 1310 ojos de 1111 pacientes, de los cuales solo en ocho pacientes, todos de raza blanca (caucásicos), fueron secundarios a cáncer de páncreas, con una edad promedio de 66 años, el $75 \%$ mujeres, con presentación unilateral en el $88 \%$ y con coloración amarillenta y líquido subrretiniano, y el $63 \%$ tenía el antecedente de cáncer de páncreas.

En otro estudio, Shah, et al. ${ }^{4}$, en los Estados Unidos de América, reportaron cinco casos de MC por cáncer de páncreas, de los cuales cuatro eran mujeres, con edades $>40$ años, y las características oftalmológicas más importantes que reportaron fueron la presentación unilateral, la lesión única de coloración amarillenta y el desprendimiento de retina seroso extenso. Todos los pacientes tenían el antecedente de cáncer de páncreas previo a las manifestaciones oftalmológicas.

Arango, et al. ${ }^{6}$, en Colombia, reportaron un caso clínico de una mujer de 58 años con pérdida visual como primera manifestación de cáncer de páncreas.

Considerando lo previamente descrito, nuestro paciente es un caso sumamente raro, debido a que no es frecuente que se presente baja visual como primera manifestación sistémica de cáncer de páncreas. De igual modo, la edad, el sexo y la raza de nuestro paciente son poco frecuentes en los casos de adenocarcinoma de páncreas sin signos sistémicos ni factores de riesgo de importancia para el desarrollo de la neoplasia. En general, la sobrevida de los pacientes con cáncer de páncreas a 5 años es menor del $7 \%$, y en aquellos con tumores resecables aumenta a un $15-25 \%{ }^{8}$. 


\section{Conclusión}

Las MC pueden ser la manifestación inicial de un adenocarcinoma de páncreas.

\section{Financiamiento}

El presente artículo fue autofinanciado.

\section{Conflicto de intereses}

Los autores no tienen ningún conflicto de intereses.

\section{Responsabilidades éticas}

Protección de personas y animales. Los autores declaran que para esta investigación no se han realizado experimentos en seres humanos ni en animales.

Confidencialidad de los datos. Los autores declaran que han seguido los protocolos de su centro de trabajo sobre la publicación de datos de pacientes.
Derecho a la privacidad y consentimiento informado. Los autores han obtenido el consentimiento informado de los pacientes $\mathrm{y} / \mathrm{o}$ sujetos referidos en el artículo. Este documento obra en poder del autor de correspondencia.

\section{Bibliografía}

1. Demirci $H$, Shields $C L$, Chao AN, Shields JA. Uveal metastasis from breast cancer in 264 patients. Am J Ophthalmol. 2003;136:264-71.

2. Arepalli S, Kaliki S, Shields CL. Choroidal metastases: origin, features, and therapy. Indian J Ophthalmol. 2015;63:122-7.

3. Shields CL, McMahon JF, Atalay HT, Hasanreisoglu M, Shields JA. Retinal metastasis from systemic cancer in 8 cases. JAMA Ophthalmol. 2014:132:1303-8.

4. Shah SU, Shields CL, Bianciotto CG, Shields JA. Pancreatic cancer metastasis to choroid. Ophthalmology. 2011;118:1-5.

5. Shields C, Welch R, Malik K, Acaba-Berrocal L, Selzer E, Newman J, et al. Uveal metastasis: clinical features and survival outcome of 2214 tumors in 1111 patients based on primary tumor origin. Middle East Afr J Ophthalmol. 2018;25:81-90.

6. Arango M, Tobón A, Correa A, Robayo J. Pérdida de la agudeza visual como primera manifestación del cáncer de páncreas: reporte de caso. Rev Soc Colomb Oftalmol. 2017;50:39-44.

7. Singh RP, Steinle NC, Bedi R, Kaiser P, Lowder CY. Retinal infiltrates secondary to metastatic squamous cell carcinoma masquerading as infectious retinitis. Retin Cases Br Reports. 2014;8:333-5

8. Kleeff J, Korc M, Apte M, La Vecchia C, Johnson CD, Biankin AV, et al. Pancreatic cancer. Nat Rev Dis Primers. 2016;2:16022. 